DOI: http://dx.doi.org/10.22483/2177-5796.2017v19n2p397-415

\title{
Funções e formas de ingresso dos/as gestores/as escolares nas redes estaduais paulista e paranaense ${ }^{1}$
}

\author{
Nathália Delgado Bueno da Silva \\ Graziela Zambão Abdian
}

\begin{abstract}
Resumo: $\mathrm{O}$ artigo analisa as relações entre as formas de ingresso e as funções delineadas para os/as gestores/as escolares nas redes estaduais paulista e paranaense, relacionando os dois temas com as questões nacionais e estaduais, históricas e teóricas. Metodologicamente, procedemos à sistematização e análise documental dos dois estados e analisamos entrevistas semiestruturadas com quatro gestores/as de cada um dos estados. Nacionalmente, há multiplicidade de formas de ingresso nas redes estaduais do país, com predomínio das formas mistas e, especificamente nas redes analisadas, há relações intrínsecas entre a função/atuação do/a gestor/a e sua forma de ingresso nas escolas, assim como apontado na teoria em administração/gestão escolar. Os/as gestores/as eleitos no Paraná possuem maior possibilidade de vivenciarem sua função de acordo com as expectativas da comunidade do que os gestores/as concursados de São Paulo, que possuem especificações governamentais que limitam sua função a determinadas atividades de cunho tecnoburocrático.
\end{abstract}

Palavras-chave: Função dos gestores na escola pública. Gestores eleitos no Paraná. Gestores concursados em São Paulo. Gestão democrática da escola pública.

\section{Functions and forms of entry of school administrators in the state networks of São Paulo and Paraná}

\begin{abstract}
The article analyzes the relations between the forms of entry and the functions outlined for gazetted school administrators/manangers in the state networks of São Paulo and Paraná, linking the two themes with national and state, historical and theoretical issues. Brazil presents a scenario that facilitates the entry of this manager in different ways, thus enabling state that there are different positions of these in school networks as soon as it was noted that there is direct interference between the way of entering with its possibility of action. To analyze these issues from the state networks of São Paulo and Paraná, where both have historical identity about their choice for this entry, we found from the analysis of documents, that government policies of these states give different directions about administration/school management that are linked to the functions of managers in school. Thus, these elements function and form of provision, present as a specific condition of the administration / school management in public schools.
\end{abstract}

Keywords: Role of managers in public school. Elected managers in Paraná. Gazetted managers in São Paulo. Democratic management of public schools.

\footnotetext{
${ }^{1}$ CAPES (Pesquisa vinculada a bolsa do Curso de Mestrado da autora Nathália Delgado Bueno da Silva).
}

Quaestio, Sorocaba, SP, v. 19, n. 2, p. 397-415, ago. 2017. 


\section{Introdução}

Neste artigo, pretendemos analisar as relações entre as formas de ingresso e as funções delineadas para os/as gestores/as escolares nas redes estaduais paulista e paranaense, relacionando os dois temas - ingresso e função - e os articulando às questões nacionais e estaduais, históricas e teóricas, no sentido de buscar compreender em que medida e como os temas se vinculam à configuração da gestão da educação e escolar de cada estado. Para isto, procederemos à sistematização e análise documental presente nos dois estados e traremos algumas conclusões das análises das entrevistas semiestruturadas realizadas com quatro gestores/as de cada um dos dois estados.

A análise não pretende generalizar seus dados, mas, sobretudo, identificar e explorar as possibilidades que existem nas diferentes redes de ensino quanto ao delineamento de suas respectivas formas de gestão do sistema e das escolas. Buscamos, neste artigo, analisar como e porque as redes estaduais, paranaense e paulista, são do jeito que são no que diz respeito à forma de ingresso do/a gestor/ a escolar e suas relações com a atuação deste/a profissional. Destacamos alguns aspectos que justificam a importância do trabalho e as contribuições com o debate na educação, particularmente com a Política e Administração da educação.

No âmbito da reforma do Estado realizada no governo Fernando Henrique Cardoso (década de 1990), ocorreram várias alterações na política e administração da educação no Brasil, que atingiram todos os níveis e modalidades de ensino, sendo algumas delas regulamentadas com a publicação da Emenda Constitucional n. 14/96, da Lei 9.424/96, que regulamentou o FUNDEF (Fundo Nacional de Desenvolvimento do Ensino Fundamental e de Valorização do Magistério, atualmente FUNDEB - Fundo Nacional de Desenvolvimento da Educação Básica) e com a Lei de Diretrizes e Bases da Educação Nacional n. 9.394/96 (OLIVEIRA, 2010).

Segundo Cury (2006), a LDBEN evidenciou problemas complexos da educação nacional. Como primeiro problema, o autor cita que o seu caráter nacional se contrapõe à autonomia real dos estados membros da Federação, que sofrem consequências de um modelo hierárquico da União, que conta com um Poder Executivo imperialista em todos os sentidos. Um segundo problema é o caráter nacional e uniforme imposto pela Lei para uma nação evidentemente desigual em sua formação histórica, étnica e social, como é o caso da existência de uma base curricular nacional. 
Apesar disso, o autor evidencia eixos claros e pontos que tipificam a Lei: "a flexibilidade": contendo descentralização das competências nos artigos 9 $10,11,16,17$ e 18 ; desregulamentação de controles cartoriais: art. 11,12 e 13 e autonomia das instituições, proposta pedagógica e registro de diplomas, etc.; desescolarização: art. 24, II, “c”; $1^{\text {o; }} 38 \S 2^{\circ}$ e 42 . Em contraponto à flexibilidade, entretanto, pode haver a regulamentação, que é amparada juridicamente pelo intérprete da Lei; e "a Avaliação" que, segundo o autor, acaba por negar a existência de um sistema nacional de educação e afirma a existência de um sistema nacional de avaliação (CURY, 2006).

Werle, Thum e Andrade (2008), em perspectiva semelhante, identificam que apesar de existirem movimentos de recentralização na educação, há espaços legais que possibilitam a participação e fortalecimento de autonomia política dos governos locais. Entretanto, para as autoras, “[...] possibilitar implica estabelecer, instituir, fundar, exige olhar inquisidor, que busca a forma de instaurar, desenvolver, retomar, reinventar procedimentos democráticos" (WERLE; THUM; ANDRADE 2008, p. 81). Neste contexto, há a possibilidade, no que tange à gestão democrática do ensino público, de cada sistema direcionar o seu entendimento sobre o assunto.

A forma de ingresso do/a gestor/a escolar é um dos aspectos que coube aos sistemas o direcionamento às suas escolas e, devido à multiplicidade de práticas e entendimentos, buscamos encontrar pesquisas que analisassem o tema. No banco de teses e dissertações em Educação da Capes, não foram encontradas pesquisas que trouxessem em seu tema, especificamente, a função do/a gestor/a eleito/a no estado do Paraná e a função do/a gestor/a concursado/a no estado de São Paulo. Os objetivos propostos neste artigo, particularmente, podem contribuir com as discussões na área, as quais demonstram lacunas ao tratar de tais temas - função e formas de ingresso deste profissional - de forma articulada e, também, nos estados escolhidos para compor a análise.

A literatura da área contempla, às vezes direta outras indiretamente, as temáticas, no entanto, não trabalham com as especificidades estaduais, conforme nossa proposta. Ademais, a função do/a gestor/a escolar, especificamente, ganhou destaque nos âmbitos acadêmico e social, principalmente após as reformas dos anos 1990, já analisadas por inúmeros pesquisadores (OLIVEIRA, 2010; OLIVEIRA, 2005; BALL, 2006; ABDIAN, 2010; KRAWZCYK, 2008). Isto se deu porque o novo gerencialismo, típico do mundo empresarial, passou a se efetivar por meio de sua carreira e a ela foi computada o êxito ou não das escolas nos resultados mensurados pelas avaliações externas e em larga escala. Por outro lado, no mesmo período, como desdobramento 
do processo de descentralização, cada estado e município, com seu próprio sistema, puderam vivenciar seus procedimentos de ingresso do/a gestor/a escolar. É possível inferir que houve multiplicidade de formas de ingresso que, concomitantemente, foram de encontro ou ao encontro das diretrizes internacionais e/ou nacionais sobre a função do/ gestor/a na escola.

Anteriormente à promulgação do Plano Nacional de Educação, publicado sob a Lei Federal n. 13.005 de 2014 (BRASIL, 2014), encontrava-se em aberto, em âmbito nacional, o direcionamento quanto à forma de ingresso do/a gestor/a de escola. A Lei Federal supracitada, pela primeira vez na história da educação brasileira, em sua meta 19 e devidas estratégias, aponta critérios para subsidiar o ingresso de gestores/as nas escolas, o que consubstanciou a importância da temática a ser tratada em nossa pesquisa e na análise deste artigo.

Diante do breve cenário descrito, o presente artigo apresenta uma discussão bastante interessante ao analisar histórica, teórica, e estadualmente, a função e a forma de ingresso do/a gestor/a escolar nos estados do Paraná e em São Paulo. Intencionamos, com a análise, evidenciar as particularidades de cada estado, os limites e as possibilidades já vivenciadas em nosso país e abrir novos pontos para debate aos leitores pertencentes a outras regiões e/ou países. Devido aos limites espaciais do artigo científico, optamos por trazer, inicialmente, uma discussão teórica das formas de ingresso do/a gestor/a escolar juntamente com a apresentação das formas privilegiadas por cada estado da federação, cujo mapeamento fora realizado via busca em cada site das respectivas secretarias estaduais de educação, no ano de 2015. Em seguida e precedendo as considerações finais, nas quais trazemos algumas novas problematizações, analisamos como está direcionada as formas de ingresso e suas articulações com a função do/a profissional em pauta nos estados do Paraná e São Paulo.

\section{Formas de ingresso do/a gestor/a de escola e expectativas de sua função}

Conforme pontuou Dourado (2001), não devemos correr o risco de tratar da forma de ingresso do/a gestor/a de escola sem refletir de forma conjunta à atuação deste profissional. Concordamos com o autor porque a forma de escolha assumida pelos estados e/ou municípios não é neutra e interfere nos delineamentos da administração/gestão da escola, compreendida como a organização de seu trabalho, e, desta forma, direciona a atuação do/a gestor/a.

Em estudo realizado na década de 1990, o autor detectou cinco formas de ingresso do 
diretor, sendo elas: indicação pelos poderes públicos; diretor de carreira; aprovação em concurso público; indicação por lista tríplice ou sêxtuplas e eleição direta. Já Alves (2009) indicou quatro modalidades de escolha: a indicação (técnica ou política); seleção por concurso de títulos e provas; eleições; e esquemas mistos. Tomaremos por base a classificação elaborada por Paro (2003), o qual aglutinou as formas de ingresso em: nomeação ${ }^{2}$, concurso e eleição. Acrescentaremos algumas considerações a respeito dos esquemas mistos, principalmente, quando contemplarmos as diretrizes do Plano Nacional de Educação (BRASIL, 2014).

Todas as possibilidades de ingresso representam o posicionamento dos governos estaduais acerca do que é esperado do/a gestor/a e de sua atuação, bem como demonstram uma concepção, explícita ou não, de administração/gestão escolar específica.

No que tange às concepções acerca da administração/gestão escolar, há dois posicionamentos presentes no discurso científico. Até a década de 1980, autores como Ribeiro (1968) e Alonso (1976) apoiavam-se em conceitos advindos da Teoria Geral da Administração e equiparavam a administração escolar à administração empresarial, delineando ao diretor uma função técnica baseada em direcionamentos de liderança em relação aos demais integrantes da escola.

A partir da década de 1980, há a tentativa de desvincular a administração/gestão da escola de tais princípios, refletindo acerca da relevância em considerar, principalmente a partir de Paro (1986), a especificidade do processo pedagógico e de sua administração. Em substituição ao caráter eminentemente técnico do administrador vislumbra-se um profissional com função política, representante de uma comunidade que ruma à transformação social. Para isto, a defesa acadêmica passa a se fazer pela constituição de um coletivo no interior da escola, via gestão democrática. Junto a esta concepção de administração/gestão escolar, que desvincula seus princípios à Teoria Geral da Administração e se embasa na gestão democrática, a forma de ingresso do/a gestor/a nas redes/sistemas de ensino também deve ser um ponto para reflexão. Portanto, visando a este profissional uma atuação baseada na articulação com a comunidade escolar, qual seria sua forma de ingresso mais pertinente?

Alves (2009) aponta que, até então (década de 1980), a indicação política para o ingresso de diretores era a forma mais usual, ou seja, não havia representatividade da comunidade escolar

\footnotetext{
2 Vale ressaltar que "nomear" o diretor se insere nas diferentes modalidades de seu ingresso, por exemplo, eleição ou concurso público, quando os selecionados são nomeados pelo estado em seu diário oficial, porém, utilizamos este termo em consonância com o referencial escolhido, que o apresenta como sinônimo de indicação.
}

Quaestio, Sorocaba, SP, v. 19, n. 2, p. 397-415, ago. 2017. 
na escolha do seu diretor, possibilitando, assim, uma relação mais direta entre direção e quem o indicou. Desta forma, as expectativas para a atuação do diretor o afastavam da responsabilidade em responder às necessidades da escola. Qual seria o interesse do/a gestor/a nomeado/a em se preocupar com as necessidades de sua comunidade, sendo que não houve interferência desta no seu ingresso? Ou, ainda que o diretor esboce algum interesse, ele está ameaçado se não contribuir com o que esperado por quem o nomeou, fazendo com que, de qualquer forma, os interesses da comunidade, na maioria das vezes, fiquem em segundo plano, limitando sua função a interesses partidários e estritamente governamentais.

Outra forma de ingresso que não garante a participação da comunidade escolar é o concurso público de prova e títulos. Esta modalidade de escolha é historicamente adotada no estado de São Paulo que, desde a década de 1970, possui esta prática como forma de provimento do cargo do diretor nas suas escolas estaduais ${ }^{3}$.

A opção pelo concurso faz com que o diretor ingresse nas escolas, por meio da aferição de conteúdos, no entanto, ainda que esta prática seja amplamente aceita para o ingresso de professores nas escolas, no que diz respeito ao cargo de direção, há algumas reflexões a serem consideradas. A partir do momento em que o diretor passa nesta prova, caberá a ele escolher a escola na qual atuará, ou seja, assim como não há, por parte do diretor, um conhecimento prévio acerca das necessidades desta escola, também não há, pela comunidade escolar, o conhecimento acerca deste profissional. E, considerando a necessidade de uma atuação do diretor de forma articulada a esta comunidade, o que demanda uma dimensão política ${ }^{4}$ a este profissional, a aferição de conhecimentos que o concurso propõe não nos parece suficiente.

Consideramos, assim como Paro (2010), que um critério estritamente técnico para o ingresso do/a gestor/a na escola é limitado. Há que se reconhecer o concurso como processo de escolha legítima ao averiguar as competências técnicas, porém, não é possível considerá-lo suficiente como forma de escolha deste profissional, uma vez que suas atribuições transpõem elementos que o concurso pode avaliar. Estas dizem respeito à função política de representante da vontade da comunidade.

\footnotetext{
${ }^{3}$ Segundo Cortina (1999), já na década de 1930, o estado de São Paulo optava para o ingresso de diretores através do concurso público. Segundo a autora, o primeiro concurso para diretores aconteceu no ano de 1933, com o Decreto n. 5884 de 21 de abril, que instituiu o Código de Educação do Estado de São Paulo. Este documento previa o concurso de títulos e provas para diretor de grupos escolares.

${ }^{4}$ Essa dimensão política se constitui em ações de mediação, sensibilidade para antecipar situações e a capacidade de negociação considerando as de pessoas envolvidas e os objetivos escolares em sua forma global.
}

Quaestio, Sorocaba, SP, v. 19, n. 2, p. 397-415, ago. 2017. 
As formas de ingresso em pauta explicitam uma concepção de administração/gestão escolar de cunho empresarial porque não reconhecem as especificidades da comunidade escolar e a função política da educação como relevantes na escolha de seu/sua gestor/gestora. Elas acabam por disponibilizar um/uma profissional externo/a aos interesses e especificidades da comunidade escolar.

Outra forma de ingresso é a eleição direta dos/as gestores/as escolares via comunidade escolar. Pensando na democratização da escola pública, os autores (LUCE; MEDEIROS, 2006; SOUZA, 2006; PARO, 2003) que defendem a eleição apontam que a população deve ter sua participação ampliada às tomadas de decisões, o que inclui o envolvimento no processo de escolha de seus dirigentes. No entanto, há o reconhecimento de que esta prática, em si, não garante que o diretor eleito tenha uma atuação pautada no envolvimento com sua comunidade e na democratização da educação e das práticas no interior das escolas, visto que os obstáculos para tal são inúmeros.

Diferentes pesquisas indicam, no entanto, que quando a comunidade escolar opta de forma direta pelo/a seu/sua gestor/gestora, há ampliação considerável da participação dos pais e de outros segmentos na escola (LUCE; MEDEIROS, 2006). O/a gestor/a ingresso por meio da eleição direta é um profissional que já estava inserido na escola em outro cargo, seja ele professor ou funcionário, de acordo com as diretrizes estaduais e/ou municipais para tal $^{5}$. De certa forma, está mais evidente seu envolvimento político com a comunidade e não será excluída sua formação técnica como professor/a para o exercício profissional de gestor/a da escola. Paro (2003) destaca uma questão interessante ao apontar que as contradições entre a função política e a função burocrática se explicitam com essa forma de ingresso do/a profissional gestor/a, considerando, sobretudo, que ele/a passa a ter um compromisso com quem o elegeu (comunidade), mas não deixa de ter de cumprir as tarefas advindas do governo ao qual sua escola está submetida.

Na mesma perspectiva de Paro (2003), Dourado (2001) não imputa à eleição de gestores/as à garantia da democratização da gestão, mas defende

[...] a tese enquanto instrumento para o exercício democrático. A nosso ver, é fundamental ampliarmos os horizontes da democratização da gestão, enfatizando,

\footnotetext{
${ }^{5}$ Como cada sistema define, em lei, a forma e os procedimentos para o ingresso do/a profissional gestor/a, há diferentes formas no Brasil, no entanto, a maioria privilegia o/a professor/ da escola e que tenha alguns anos de exercício profissional naquele local.

Quaestio, Sorocaba, SP, v. 19, n. 2, p. 397-415, ago. 2017.
} 
conjuntamente, a forma de escolha e o exercício da função, de modo a não incorrermos nos riscos de uma pretensa neutralidade frente às modalidades de escolha - normalmente autocráticas. Assim, a forma de provimento no cargo pode não definir o tipo de gestão, mas, certamente, interfere no curso desta. Neste contexto, visualizar a eleição como ação terminal é incorrer no equívoco de se negar o caráter histórico do processo, pois a eleição deve ser vislumbrada como um instrumento a ser associado a outros na luta pela democratização possível das relações escolares (DOURADO, 2001, p. 85).

Para analisar as redes estaduais a que nos propusemos, levantamos, um a um, no site de cada secretaria de educação dos respectivos estados da federação, a forma de ingresso deste profissional, no ano de 2015. A sistematização dos dados está expressa no quadro abaixo:

Quadro 1 - Mapeamento dos estados brasileiros referente à forma de ingresso do/a gestor/a de escola nas redes públicas estaduais no ano de 2015.

\begin{tabular}{|c|c|}
\hline Estados Brasileiros & Processo de escolha do diretor escolar na rede estadual de ensino (2015) \\
\hline Rio Grande do Sul & Eleição direta \\
\hline Santa Catarina & Curso de formação/ Certificação do plano de gestão/ Comunidade escolar elege o plano \\
\hline Paraná & Eleição direta \\
\hline São Paulo & Concurso público: Prova conhecimentos e títulos \\
\hline Mato Grosso do Sul & Eleição direta \\
\hline Minas Gerais & Prova de Conhecimentos/Eleição \\
\hline Rio de Janeiro & Prova de Conhecimentos/Avaliação perfil/Curso de formação/Indicação \\
\hline Espírito Santo & Seleção de perfil do candidato/Entrevista/Indicação \\
\hline Goiás & Curso de formação/Prova conhecimentos/Eleição \\
\hline Distrito Federal & Eleição direta/Curso capacitação \\
\hline Mato Grosso & Ciclo de estudos/Eleição \\
\hline Rondônia & Eleição direta \\
\hline Acre & Curso capacitação/Eleição \\
\hline Amazonas & Não foi encontrado \\
\hline Roraima & Não foi encontrado \\
\hline Pará & Eleição direta \\
\hline Amapá & Eleição/Lista tríplice/Indicação \\
\hline Maranhão & Curso capacitação/Prova conhecimentos/Eleição \\
\hline Piauí & Eleição direta \\
\hline Tocantins & Indicação \\
\hline Bahia & Prova de conhecimentos/Eleição \\
\hline Sergipe & Curso capacitação/Eleição/Lista tríplice/Indicação \\
\hline Alagoas & Eleição direta \\
\hline Pernambuco & Curso capacitação/Prova de conhecimentos/Eleição/Lista tríplice/Indicação \\
\hline Paraíba & Eleição direta \\
\hline Rio Grande do Norte & Curso capacitação/Eleição \\
\hline Ceará & Eleição direta \\
\hline
\end{tabular}

Fonte: SILVA, N. D. B. Funções e formas de provimento dos diretores das redes estaduais paulista e paranaense. 2016. 127f. Dissertação (Mestrado em Educação) - Universidade Estadual Paulista Júlio de Mesquita Filho, Marília, 2016. p. 40. 
É possível destacar que a eleição direta para gestor/a é a segunda forma mais usual como modalidade de ingresso, estando presente em nove estados. Já a seleção mais usual é a mista, estando presente em catorze estados por meio de processos que incluem: eleição via comunidade articulada a provas específicas ou eleição e indicação mediante lista tríplice, ou até mesmo cursos de capacitação como pré-requisito à eleição, entre outros.

Tendo em vista que as formas de ingresso do/a gestor/a pressupõem determinadas expectativas à sua atuação, bem como demonstram concepções específicas acerca da administração/gestão escolar, as modalidades mistas de escolha merecem destaque, pois, mesmo que haja a participação da comunidade escolar na escolha do/a gestor/a, esta é limitada porque anteriormente ao processo eleitoral, ou depois, há um direcionamento via diretrizes governamentais, por meio de provas específicas, cursos de capacitação, listras tríplices etc. Desta forma, esta forma pressupõe uma definição do governo do estado em atribuir à escola uma participação restrita e a ele tutelada. Ao optarem pelos modelos mistos, há uma imprecisão acerca do que é esperado da função deste/a gestor/a, bem como da própria concepção de administração/gestão escolar na qual se vincula. Por exemplo, sendo o/a gestor/a eleito/a via comunidade escolar, e, devendo este/a passar posteriormente por uma prova específica para assumir a direção, há a valorização das dimensões políticas e técnicas da função, por parte do governo que a institui, no entanto, questionamos a legitimidade dos aspectos políticos, considerando, sobretudo, que se tal candidato/a não passar na prova, não poderá assumir a direção. Ou seja, a aferição dos conhecimentos é mais relevante para o ingresso do/a gestor/a do que sua atuação profissional e política na escola.

Ainda que a eleição direta para gestores/as seja a prática mais defendida pelos autores e por comunidades escolares de diversos estados e municípios, justamente por indicar que a função do profissional estará mais fortemente atrelada aos interesses da comunidade escolar, notamos que a eleição vinculada a outras formas de provimento ainda predomina no cenário educacional brasileiro. Este fato nos chama atenção porque os governos fazem intermediação na seleção mediante provas, cursos de capacitação, ou da indicação final, conforme acontece em Sergipe, Pernambuco e Amapá.

Tratando-se das provas e cursos de capacitação que são anteriores ao processo eleitoral via comunidade escolar, a intermediação do governo se faz como provedor de um perfil específico, na qual ele seleciona por mérito e desempenho. Em relação aos cursos, 
especificamente, o governo pode atuar na seleção de conteúdos que contemplem seus pressupostos. Assim, fica a cargo da escola optar pelos profissionais anteriormente selecionados, o que pode acarretar, de qualquer forma, uma verticalização de poder do governo em detrimento da comunidade escolar.

No caso dos processos eleitorais que ocorrem anteriormente a outras modalidades de seleção, a influência do governo também acontece e merece ser refletida, pois, ainda que sua escolha final seja advinda de um profissional que a escola selecionou, o diretor também será avaliado pelo governo, que respeitará suas expectativas, as quais nem sempre refletem as requeridas pela escola.

Em pesquisa realizada na década de 1990, no âmbito das experiências estaduais e nos municípios das capitais, Dourado (2001) constatou que a eleição direta era a forma mais usual. Nossos dados empíricos indicam ser a eleição a forma mais recorrente entre os estados, porém, não a eleição direta. Podemos dizer que houve alterações nas políticas públicas estaduais para o processo de seleção dos/as gestores/as da década de 1990 para os anos 2015, no entanto, como Dourado (2001) incluiu os municípios das capitais, estas alterações não podem ser afirmadas, pois há um número maior que o nosso de localidades que entraram em seu objeto de estudo.

De qualquer forma, frente aos dados que coletamos em 2015, notamos que houve, por grande parte dos estados, esta inserção da comunidade escolar nos processos de escolha de seus/as gestores/as.

Apesar das ponderações que fizemos a respeito das formas mistas de ingresso do/a gestor/a escolar, elas são a forma mais usual entre os estados. E, com a publicação da Lei Federal que institui o Plano Nacional de Educação (BRASIL, 2014), a expectativa do governo federal é que elas se concretizem em todos os sistemas educacionais do país. Indicamos a necessidade de estudos específicos que possam retratar, a partir da multiplicidade de historias estaduais e/ou municipais, os impactos de tal determinação nacional. Este movimento já vem sendo feito por parte dos integrantes do grupo de pesquisa, a qual esta pesquisa se vincula, que estão analisando as relações que se constituíram e hegemonizaram concepções de democracia no momento de elaboração dos Planos Estaduais e Municipais de Educação, cuja obrigatoriedade passou a vigorar com a aprovação da Lei Federal que instituiu o Plano Nacional. A seguir, analisamos as especificidades paulista e paranaense no que diz respeito ao ingresso do/a gestor/a escolar. 


\section{O/a gestor/a eleito/a na rede estadual do Paraná e o/a gestor/a concursado/a na rede estadual de São Paulo}

No estado do Paraná, o diretor da rede pública estadual ingressa por meio de eleição direta via comunidade escolar, sendo assim, integrantes da escola que possuem o cargo de professor, coordenador ou funcionário, podem vir a ser designados na função de direção.

Segundo Cunha (1991), o governo deste estado foi o primeiro a efetivar o processo eleitoral para diretores de escola, no ano de 1983, no entanto, este estava atrelado à Lista Tríplice. No decorrer dos anos, notam-se que as formas de ingresso não foram lineares, indo desde a supracitada eleição direta até à prova específica para o cargo de gestor/a, como aconteceu no ano de 2001. No entanto, a eleição, mesmo que por vezes articulada às outras modalidades, é a mais representativa deste estado, desde a década de 1980. E, a partir de 2003, as eleições diretas via comunidade escolar se institucionalizam e passam a ser regulamentadas pela Lei $\mathrm{n} .14 .231^{6}$ do mesmo ano.

Diferentemente, a rede estadual de São Paulo apresenta a mesma forma de ingresso dos gestores/as da rede pública estadual, desde a década de 1970: o concurso público de provas e títulos. Ainda que a modalidade se mantenha, suas especificidades foram alteradas no decorrer dos anos, principalmente quanto aos critérios para concorrer ao cargo às bibliografias propostas. Desta forma, enquanto na rede estadual paranaense o diretor é uma função designada que contempla diferentes cargos, na rede estadual paulista, há o cargo de diretor de escola.

Para analisar as concepções e expectativas de um e outro governo estadual acerca da atuação do/a gestor/a, a partir de sua forma de ingresso, privilegiaremos suas diretrizes estaduais mais atuais, por considerarmos o espaço restrito do artigo. Apresentamos, no caso do Paraná, a Resolução n. 4122/2011 que regulamentou o mandato de direção entre os anos de 20122014 (PARANÁ, 2011); e, se tratando de São Paulo, os subsídios do último concurso público para diretor de escola, que ocorreu em 2007, e a Lei Complementar n. 1.256/2015 que traz especificações acerca da "avaliação periódica para diretores" (SÃO PAULO, 2015). Desde os critérios para concorrer à função ou cargo de gestão, os estados apresentam diferentes posicionamentos. No Paraná, tal Resolução institui que o funcionário possua curso

\footnotetext{
${ }^{6}$ Esta Lei foi revogada pela Lei n.18590 de 13 out. 2015.

${ }^{7}$ Este mandato se estendeu até o final de 2015.

Quaestio, Sorocaba, SP, v. 19, n. 2, p. 397-415, ago. 2017.
} 
superior em licenciatura, já em São Paulo, é indicado que se tenha pelo menos um dos títulos: diploma, devidamente registrado, de licenciatura plena em Pedagogia; diploma de Mestrado ou Doutorado, na área de Educação; serão considerados somente os cursos que apresentem um estreito vinculo de ordem programática com a natureza da atividade inerente ao trabalho dos integrantes da classe de Diretor de Escola (Gestão Escolar); certificado de conclusão de curso devidamente aprovado, de pós- graduação, em nível de especialização, na área de formação de especialista em Educação (Gestão Escolar), com carga horária de, no mínimo, 800 (oitocentas) horas. Ou seja, para realizar o concurso para gestor/a, o profissional que não tenha a licenciatura em Pedagogia deve possuir pós-graduação na área da Educação, com estas devidas especificidades. No Paraná, a formação inicial em licenciatura é o suficiente. Com tais especificações, consideramos que são deixadas para segundo plano as funções articuladas ao processo pedagógico, uma vez que a formação inicial em Pedagogia privilegia estes conteúdos e outra formação não necessariamente os fazem.

Em relação ao tempo de serviço, as cobranças são ainda mais discrepantes, pois, enquanto São Paulo exige que o candidato tenha no mínimo 8 anos de exercício, efetivamente prestado no magistério, a Resolução do Paraná aponta um mínimo de noventa dias ininterruptos de trabalho no estabelecimento que pretende dirigir, desta forma, abrange aqueles que ainda estão em período probatório de seu cargo.

Estas são algumas especificidades que desde os critérios de seleção vão estabelecendo diferenças que configuram as expectativas de ambas as realidades por meio de suas diretrizes estaduais, bem como, da própria atribuição ao/a gestor/a enquanto cargo em São Paulo, ou função no Paraná.

Quanto às expectativas dos governos estaduais acerca da atuação do/a gestor/a, as divergências se mantêm, reforçando a reflexão inicial de que estando os gestores/as inseridos por meio de diferentes formas de ingresso, há também diferentes concepções de administração/gestão escolar que embasam as redes públicas, refletindo em seu trabalho cotidiano na escola.

A Resolução n. 4122/2011 (PARANÁ, 2011), que regulamentou o mandato dos/as gestores/as da rede estadual no Paraná entre os anos de 2012-2014, apresenta 83 artigos que descrevem o processo eleitoral de forma a situar tanto aqueles que participaram da supervisão, coordenação e execução do mesmo, quanto os diretores que irão se candidatar. Em meio às 
especificações, a Resolução aponta elementos norteadores a constar no Plano de Gestão que deverá ser elaborado pelos candidatos.

Este Plano destaca, principalmente por meio dos indicadores que deverão constar no quadro de metas do diretor, aspectos referentes às expectativas governamentais sobre a função da direção, pois especifica quais devem ser os campos de atuação e preocupação do diretor em seu mandato. O quadro de metas está dividido em seis indicadores, que são: 1) Gestão de resultados educacionais; 2) Gestão participativa/democrática; 3) Gestão pedagógica; 4) Gestão de inclusão/socioeducação; 5) Gestão de pessoas; 6) Gestão de serviços de apoio (recursos físicos e financeiros). E em cada um destes indicadores devem ser abordados os temas "A escola que temos hoje (potencialidades e dificuldades)"; "A escola que pretendemos"; "O que vamos fazer (ações em curto, médio e longo prazo)".

Dentre os seis indicadores propostos pelo governo estadual, há uma maior incidência de elementos que preconizam ao gestor/a um trabalho conjunto com sua comunidade. Assim, as expectativas desta rede estadual, ao delinear as dimensões de sua atuação, corrobora com o aspecto político da função do/a gestor/a, que dentre os itens 2, 3, 4 e 5 estão presentes, em detrimento de atividades de cunhos técnico e burocrático, presentes nos itens 1 e 6.

Os autores da administração/gestão escolar, ao defenderem as eleições diretas para gestores/as, indicam que há, por parte do escolhido, uma valorização à sua comunidade escolar (quem o elegeu), justamente por esta deliberar acerca de seu ingresso. Ampliamos esta reflexão, indicando que a rede estadual, ao optar por esta modalidade, também reconhece que há, na prática de atuação do/a gestor/a, uma relação direta com sua comunidade, pois, no caso do Paraná especificamente, as diretrizes ampliam a relação gestor/a e comunidade para além do processo eleitoral, logo que é determinado que o Plano de Gestão tenha predominância de aspectos que reforçam estes aspectos.

Assim, este delineamento via diretrizes estaduais, ao estabelecer a ampliação da relação diretor e comunidade para além do processo eleitoral, também evidencia, tanto aos candidatos quanto aos demais, que a vivência democrática instituída na eleição não é um fim em si mesmo, mas um princípio a ser vivenciado constantemente na escola. 
Em entrevista ${ }^{8}$ com gestores/as eleitos/as na rede estadual paranaense, foi possível observar que há em suas atividades diárias uma relação próxima à comunidade escolar, logo que os/as entrevistados apontam pautar suas atribuições nas demandas e necessidades escolares que vão surgindo no dia a dia. Desta forma, não há um delineamento a priori de sua atuação, ou uma diretriz que embase suas atividades cotidianas. Aliás, ainda que tais gestores/as mencionem que haja um documento estadual acerca de suas atribuições, não sabem especificar seus elementos e afirmam que este não consta na escola, além de também apontarem para a escassez de cursos de formação continuada propostos por seu governo, afirmando que "antigamente" este era mais recorrente. No entanto, quando questionados acerca de suas relações com o governo do estado, são unânimes em dizer que este interfere em seu trabalho por meio de demandas burocráticas, que por vezes dificultam e/ou atrasam seu trabalho pedagógico e político na escola.

Confrontando os elementos das diretrizes estaduais e da fala dos/as gestores/as, notamos haver autonomia relativa na atuação profissional, no sentido de que estes indicam que suas atividades são organizadas pelos próprios membros da gestão de sua escola. Como já mencionamos, estes se pautam em demandas diárias, o que demonstra uma relação mais direta entre com a comunidade do que com as diretrizes do governo estadual.

Analisando os concursos públicos para gestores/as na rede estadual paulista, Hojas (2011) demonstra que há no decorrer dos anos uma abrangência significativa de bibliografias sugeridas e questões de provas que se pautam em uma perspectiva de administração empresarial. Nos concursos após a década de 1980, há a inserção de autores e conteúdos que trazem a gestão democrática e elementos de uma administração/gestão pensada a partir das especificidades da escola, no entanto, a perspectiva antes mencionada se mantem, e por vezes, se sobressai, ou seja, a consideração da escola como uma empresa.

Nas escolas da rede estadual paulista, estão atuando gestores/as que ingressaram a partir da aprovação em concursos realizados em diferentes décadas. No entanto, como há uma base comum entre as seleções, há também uma totalidade de profissionais que ingressaram com as mesmas expectativas e indicadores de sua função.

No concurso de 2007, sendo este o último realizado até então, a bibliografia proposta acerca da administração/gestão escolar se baseou em coletâneas, as quais discutem, de modo

\footnotetext{
${ }^{8}$ Foram entrevistados diretores de 4 escolas da rede pública estadual do Paraná e 4 de São Paulo. As análises de suas falas foram realizadas por meio da Análise Discursiva Textualmente Orientada (ADTO). 
geral, questões relacionadas à autonomia, liderança e trabalho coletivo, não trazendo estudos substanciais acerca desta área dentro da escola, além de se basear em perspectivas distintas sobre os temas levantados, demonstrando um progressivo arrefecimento da dimensão pedagógica da função do diretor e uma crescente orientação de seu trabalho para o estabelecimento de uma cultura escolar voltada essencialmente para o desempenho (HOJAS, 2011).

Além de haver uma escassez de estudos específicos voltados para a teoria em administração/gestão escolar, a ênfase dada no gestor/a da escola como principal responsável pelos resultados finais do processo educativo, acarreta ao profissional uma carga de liderança e de comando em relação à sua comunidade. As questões das provas, a bibliografia proposta e até mesmo os requisitos aos candidatos justificam a afirmação.

A Lei Complementar n. 1.256/2015, que traz especificações acerca da "Avaliação Periódica para os Diretores", reforça o que foi constatado nos concursos acerca do perfil esperado pelo governo do estado. Ao indicar os critérios de avaliação do/a profissional, aponta as competências e habilidades necessárias a este cargo, que são: 1) comprometimento com o trabalho e com a comunidade escolar; 2) responsabilidade; 3) capacidade de iniciativa e liderança; 4) eficiência na gestão educacional; 5) produtividade; 6) assiduidade; 7) disciplina (SÃO PAULO, 2015).

Nota-se que há a valorização de uma administração/gestão pautada na relação direta com as concepções técnicas de gestão, em detrimento de posturas políticas e pedagógicas. Dentre os sete critérios, apenas um contempla diretamente a relação entre diretor e comunidade escolar, e os demais se pautam em atribuições/competências individuais.

$\mathrm{Na}$ Lei, também há referência acerca da capacitação profissional do diretor, com a realização de curso específico. Ao especificar o objetivo desta formação continuada, o documento menciona seu "foco no desenvolvimento de competências técnicas, de liderança e gestão", bem como "sua aplicação no exercício do cargo". Desta forma, ao propor esta formação, os diretores concursados atuam na escola a partir de uma demanda já instituída, logo que um dos objetivos do curso é justamente demonstrar como garantir a aplicação das competências técnicas de liderança do diretor.

As entrevistas com os gestores/as da rede estadual paulista reforçam estes elementos, pois estes profissionais, sem exceção, afirmam possuir uma agenda a cumprir para que suas atribuições enquanto diretor/a aconteçam. Estes/as profissionais também apontam a necessidade 
que sentem em se relacionar mais diretamente com questões pedagógicas, já que na maioria de suas atribuições as atividades são burocráticas. Os/as entrevistados/as afirmam que para estabelecer uma relação mais direta com tais atividades, estendem suas devidas atribuições, ou seja, reconhecem que atribuições relacionadas ao fazer pedagógico não integram sua atuação previamente direcionada via governo de estado, o qual, também por meio de cursos de formação continuada, valoriza a formação em uma perspectiva de administração empresarial aplicada na escola.

A literatura em administração/gestão escolar indica que deve haver uma relação de reciprocidade entre a gestão e a comunidade escolar, para assim ser vivenciada uma gestão democrática na escola. Ao contrário, o governo paulista, ao instituir curso de formação, bem como uma avaliação do diretor com critérios individuais limita a função deste profissional a uma atuação técnica. A realidade da rede pública estadual paulista legitima algumas reflexões já feitas por autores da literatura os quais denunciam a face tecnocrática do/a gestor/a paulista (PARO, 1986; ABDIAN; OLIVEIRA; JESUS, 2013), principalmente no que diz respeito a este/a profissional ter sua função como "preposto" do estado, estabelecendo, assim, uma relação mais próxima deste do que com sua comunidade escolar.

\section{Considerações finais}

O objetivo deste artigo foi o de trazer a discussão sobre os temas função e ingresso do/ gestor/a escolar, visando compreender as articulações provenientes entre estes dois elementos. Subsidiamo-nos em ideias que não permitem, do ponto de vista científico, que ditemos verdades e que cheguemos a conclusões generalizáveis, mas que nos auxiliam a compreender a multiplicidade, com seus limites e potencialidades, nas diferentes redes estaduais do país.

Os dados empíricos indicam, do ponto de vista nacional, a multiplicidade de formas de ingresso nas redes estaduais do país, com predomínio das formas mistas e, especificamente nas redes analisadas, que há relações intrínsecas entre a função/atuação do/a gestor/a e sua forma de ingresso nas escolas, assim como apontado na teoria em administração/gestão escolar. Notamos que os/as gestores/as eleitos no Paraná possuem maior possibilidade de vivenciarem sua função de acordo com as expectativas da comunidade do que os gestores/as concursados de São Paulo, 
que possuem especificações governamentais que limitam sua função a determinadas atividades de cunho tecnoburocrático.

Ao optarem por determinada modalidade de ingresso, os governos estaduais delineiam a função do/a profissional por meio de suas expectativas e indicadores, fazendo com que o concurso público intensifique um perfil técnico do/a gestor/a, a partir de uma perspectiva de gestão mais alinhada à empresarial, enquanto a eleição intensifica um perfil político de atuação, pautando-se principalmente em elementos alinhados à gestão pensada a partir das especificidades da comunidade escolar.

Finalmente, destacamos algumas novas problemáticas para pesquisas na área que podem vir a contribuir com o avanço das discussões e práticas de gestão, sendo elas: quais foram os impactos da determinação de obrigatoriedade de elaboração dos Planos Estaduais e Municipais no que tange à forma de ingresso do/a gestor/a escolar? As redes estaduais e municipais alteraram suas formas de ingresso a partir da elaboração desta Lei? Como se deu este processo, ele incluiu Os/as profissionais e a comunidade? Quais foram os sentidos construídos a respeito da gestão democrática da educação? À parte estas questões, há outras que aqui foram tangenciadas ou indiretamente contempladas e por outros pesquisadores já destacadas como carentes de investigações, uma delas é a questão de gênero na profissional do/a gestor/a: como ela se faz presente na forma de ingresso?

Esperamos que as análises dos dados aqui trazidas e as questões suscitadas de nossa pesquisa venham a contribuir com avanços na área da gestão e também com as vivências dos/as profissionais que estão diariamente nas escolas públicas de nosso país.

\section{Referências}

ABDIAN, G. Z. Escola e avaliação em larga escala: (contra) proposições. In: WERLE, Flávia Obino Correa (Org.). Avaliação em larga escala: foco na escola. São Leopoldo: Oiko; Brasília: Líber Livro, 2010.

ABDIAN, G. Z.; OLIVEIRA, M. E. N.; JESUS, G. de. Função do diretor na escola pública paulista: mudanças e permanências. Educação \& Realidade, Porto Alegre, v. 38, n. 3, p. 977-998, jul./set. 2013.

ALONSO, M. O papel do diretor na administração escolar. São Paulo: Difel, 1976.

ALVES, F. C. Mapeamento das políticas de escolha de diretores da escola e de avaliação na rede pública das capitais brasileiras. Rev. Bras. Est. pedag., Brasília, v. 90, n. 224, p. 71-86, jan./abr. 2009.

BRASIL. Lei Federal no 13.005/2014. Aprova o Plano Nacional de Educação. 2014. Disponível em: <http://www.planalto.gov.br/ccivil_03/_ato2011-2014/2014/lei/113005.htm>. Acesso em: 17 fev. 2015. 
BALL, S. Sociologia das políticas educacionais e pesquisa crítico-social: uma revisão pessoal das políticas educacionais e da pesquisa em política educacional. Currículo sem Fronteiras, Rio Grande do Sul, v. 6, n. 2, p. 10-32, jul./dez. 2006.

CORTINA, R. L. Burocracia e educação: o diretor de escola no Estado de São Paulo. Araraquara: UNESP; São Paulo: Cultura Acadêmica Editora, 1999.

CUNHA, L. A. Educação, Estado e democracia no Brasil. São Paulo: Cortez, 1991.

CURY, C R. J. LDB: Lei de Diretrizes e Bases da Educação (Lei 9.394/96). 10. ed. Rio de Janeiro: DP\&A, 2006.

DOURADO, L. F. A escolha de dirigentes escolares: políticas e gestão da educação no Brasil. In: FERREIRA, N. S. C. (Org.). Gestão democrática da educação: atuais tendências, novos desafios. São Paulo: Cortez, 2001. p. 77-95.

HOJAS, V. F. Formação e função do diretor de escola: análise a partir dos concursos públicos realizados na rede estadual de ensino de São Paulo (1979-2007). 2011. 113f. Dissertação (Mestrado em Educação) - Faculdade de Filosofia e Ciências, Universidade Estadual Paulista, Marília, 2011,

KRAWCZYK, N. Em busca de uma nova governabilidade na educação. In: OLIVEIRA, D. A. (Org.). Política e gestão da educação. 2. ed. São Paulo: Autêntica, 2008. p. 61-74.

LUCE, M. B. M.; MEDEIROS, I. de. Gestão escolar democrática: concepções e vivências. Rio Grande do Sul: UFRGS, 2006.

OLIVEIRA, D. A. Regulação das políticas educacionais na América Latina e suas consequiências para os trabalhadores docentes. Educação \& Sociedade, Campinas, v. 26, n. 92, p. 753-775, out. 2005.

OLIVEIRA, D. A. Mudanças na organização e na gestão do trabalho na escola. In: OLIVEIRA, D. A.; ROSAR, M. F. F. (Org.). Política e gestão da educação. 3. ed. Belo Horizonte: Autêntica, 2010.

PARANÁ. Secretaria de Estado da Educação - SEED. Resolução n. 4122/2011 - GS/ SEED. Curitiba: SEED, 2011. Disponível em: <http://www.educacao.pr.gov.br/arquivos/File/resolucoes/resolucao 41222011.pdf>. Acesso em: 23 fev. 2014.

PARO, V. H. Administração escolar: introdução crítica. São Paulo: Cortez, 1986.

PARO, V. H. Eleição de diretores: a escola pública experimenta a democracia. São Paulo: Xamã, 2003.

PARO, V. H. A educação, a política e a administração: reflexões sobre a prática do diretor de escola.

Educação e Pesquisa, São Paulo, v. 36, n. 3, p. 763-778, set./dez. 2010.

RIBEIRO, José Querino. Introdução à administração escolar (alguns pontos de vista). In: ADMINISTRAÇÃO ESCOLAR: edição comemorativa do I Simpósio Interamericano de Administração Escolar. Salvador: ANPAE, 1968. p. 18-40.

SÃO PAULO. Lei Complementar no 1.256, de 06 de Janeiro de 2015. São Paulo: Assembleia Legislativa do Estado de São Paulo, 2015.

SOUZA, A. R. de. Perfil da gestão escolar no Brasil. 2006. Tese (Doutorado em Educação) - Pontifícia Universidade Católica de São Paulo, São Paulo, 2006.

WERLE, F. O. C.; THUM, A. B.; ANDRADE, A. C. O sistema municipal de ensino e suas implicações para a atuação do Conselho Municipal de Educação. Revista Brasileira de Política e Administração da Educação, Porto Alegre, v. 24, n. 1, p. 79-109, jan./abr. 2008. 
415 SILVA, Nathália Delgado Bueno da; ABDIAN, Graziela Zambão. Funções e formas de ingresso dos/as gestores/as escolares nas redes estaduais paulista e paranaense.

Nathália Delgado Bueno da Silva - UNESP: Câmpus de Marília. Marília | SP | Brasil. Contato: nathdelgado89@ hotmail.com

Graziela Zambão Abdian - UNESP: Câmpus de Marília. Marília | SP | Brasil. Contato: graziela.maia@gmail.com

Artigo recebido em: 1 nov. 2016 e aprovado em: 25 jun. 2017.

Quaestio, Sorocaba, SP, v. 19, n. 2, p. 397-415, ago. 2017. 